\title{
CINE CLUB DE CALI: \\ 39 años de existencia \\ (Entrevista a Ramiro Arbeláez)
}

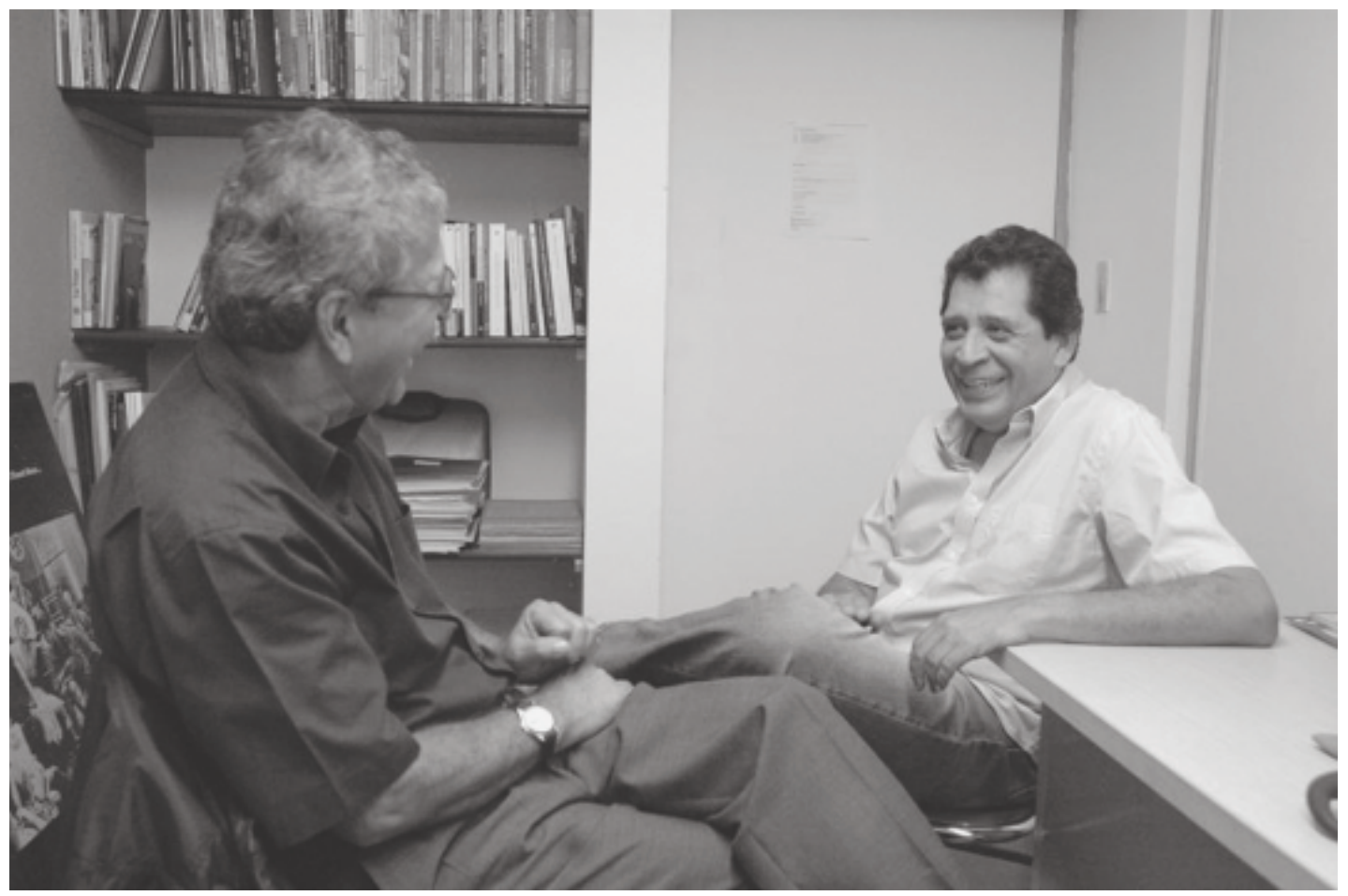

Por Hernán Toro

(hernantoro2000@gmail.com)

Profesor Titular Escuela de Comunicación Social

Facultad de Artes Integradas, Universidad del valle

Cali, Colombia

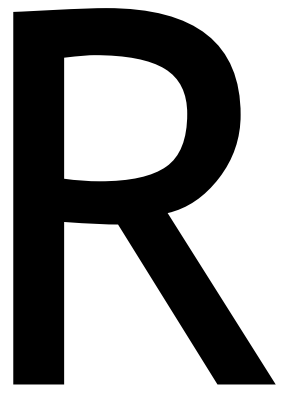

amiro Arbeláez fue miembro del Cine Club de Cali, institución atípica que, fundada en abril de 1971, apagó sus luces en 1977. Podría entonces parecer una boutade ingenua decir, como lo enuncia el titular de esta entrevista, que tiene 39 años de existencia. Pero no lo es: su incidencia en la historia del cine colombiano es creciente en la medida en que más pasan los años, un poco como ese caballo del poema de Vicente Huidobro que «crece a medida en que se aleja». El mismo Ramiro se sorprende: «Yo creo que cada vez es más importante, cada vez más citado, cada vez más referido, cada vez más estudiada su manera de operar». Esta misma entrevista es una confirmación de lo dicho: como las estrellas extinguidas (pero falsamente extinguidas, entonces), su brillo nos sigue deslumbrando. Junto a Andrés Caicedo, Luis Ospina y Carlos Mayolo (por lo demás, siempre evocados en ese orden, vaya uno a saber porqué: Caicedo, Ospina, Mayolo), Ramiro fue actor y testigo de la primera línea de combate. 
Para leer este texto, es indispensable saber que Ramiro mantiene un cierto gesto de sorna en su cara (como si nada hubiese sido serio, como si en el fondo nada importara, o sólo importara haberlo vivido con la única justificación del goce), y que nunca mira al interlocutor al hablar pues su mirada y su sonrisa están como en el otro lado de las cosas, buceando en la memoria para traer a la superficie del presente fragmentos enteros de algo que, paradójicamente, no tiene nada que ver con un naufragio sino con las cosas vivas de la existencia. Como el Cine Club de Cali, justamente; por eso tiene 39 años de existencia.

Hernán Toro (en adelante H. T.): El Cine Club de Cali de alguna manera se ha vuelto legendario. Las referencias a él son continuas y no hay texto que hable de los cine clubes en Colombia que no haga referencia a él. ¿Por qué creés que ha adquirido esa especie de santificación?

Ramiro Arbeláez (en adelante R.A): Yo creo que gran parte de ese mito corresponde a la figura de Andrés Caicedo aunque, de todas maneras, no hay que desconocer los aportes de Luis Ospina y de Carlos Mayolo y de mi mismo. Creo que la importancia que ha adquirido Andrés Caicedo con los años se ha extendido a todas sus obras, incluyendo la obra que él inicio, el Cine Club de Cali y por consiguiente al hijo de ese Cine Club, tal vez el hijo más importante, que es la Revista Ojo Al Cine. Pero en general esa santificación, como vos la llamás, es compartida por toda la obra de Andrés Caicedo, e incluye textos que, en un principio, se creían perdidos. De Andrés se sigue hablando no sólo en el ámbito local y nacional sino en el ámbito latinoamericano. En Chile, por ejemplo, Alberto Fuguet acaba de escribir Mi cuerpo es una celda, último libro sobre Andrés Caicedo. Yo creo que en gran parte se debe a eso.

H. T.: Me da la impresión de que en tu respuesta hay un sobreentendido consistente en que el Cine Club mismo no tuvo intrínsecamente el valor que se le atribuye, y que el reconocimiento que a él se hace dependiera sólo de la imagen de Andrés Caicedo.

R.A.: Sí lo tiene y me parece que está empezando a descubrirse. A lo que me refiero es que a gran parte de la sacralización o de la leyenda corresponde a la figura de Andrés Caicedo.

Afortunadamente, ha habido estudios posteriores de lo que significó el Cine Club en su época que de alguna manera le están dando una valoración más justa. Claro, el Cine Club no era sólo Andrés Caicedo, lo que ha sido motivo de tesis universitarias. Por ejemplo, en la Universidad del Valle hubo una tesis de historia dedicada al Cine Club de Cali. También ha habido partes o capítulos de otras tesis de las que he tenido conocimiento a nivel nacional: en todos esos trabajos, el Cine Club de Cali es una referencia en literatura histórica sobre el cine en Colombia. El primero que escribió en términos históricos del Cine Club de Cali fue Hernando Martínez Pardo en su libro Historia del Cine en Colombia, un libro publicado en 1978, es decir, un poquito después de que el Cine Club de Cali se había cerrado. En ese libro, Martínez le atribuye una importancia al Cine Club; y más que al Cine Club, a una especie de movimiento, aunque él no lo nombra así, que en Cali había sucedido a partir de comienzo de los años 70. Un movimiento donde figurábamos Andrés Caicedo, Luis Ospina, Carlos Mayolo, yo mismo y otra serie de personas alrededor que es largo enumerar pero que también fueron importantes, como, por ejemplo, Eduardo Carvajal. Entonces sí creo que la sacralización o el hecho de que se haya empezado a volver leyenda ha permitido que varios estudiosos se fijen en eso y traten de indagar más cómo funcionaba el Cine Club, cómo era realmente su programación o qué criterios había para programar y a partir de allí los derivados del Cine Club, como la revista Ojo al cine.

H.T.: Y a tu manera de entender las cosas, Ramiro, ¿en qué radica la importancia histórica de este Cine Club?

R.A.: Yo creo que este Cine Club fue uno de los pioneros, porque no se puede decir que fue el primero, en Colombia. Antes de nosotros había cine clubes muy importantes en Bogotá y en Medellín. Cine clubes que habían empezado en la década de los cuarenta, finales de los cuarenta, los años cincuenta, como el Cine Club de Colombia. Incluso en Cali había un antecedente muy importante en los años cincuenta, que llegó hasta los años sesenta: el Cine Club de La Tertulia. Sin embargo, el momento histórico de los años setenta y la importancia que comenzó a tener el Cine Club en algunos públicos, en algunos colectivos, tal vez lo haya vuelto mucho más trascendente 
para la gente. Yo creo que lo que hay que rescatar también es eso: el Cine Club de Cali nace en una coyuntura histórica muy especial que se está viviendo en Cali y en Colombia, y acaso también en América Latina, en la que se exige una serie de reivindicaciones de parte, sobretodo, de estudiantes y de intelectuales, de gente vinculada al arte. De alguna manera, el Cine Club canaliza unas aspiraciones de programación que de otra manera no se estaba dando en ese momento en la ciudad y canaliza también una especie de espacio de reunión, de encuentro de mucha gente al margen del poder perteneciente a ciertas instituciones artísticas en Cali. El Cine Club les sirve de medio de expresión, así su expresión sea simplemente asistir, ver la película, gozársela; en algún momento también hacíamos reuniones en la casa de Luis Ospina, etc. Pero fueron pequeños momentos de expresión de ese mismo público. Sin embargo, el mismo hecho de asistir al rito, del encuentro y de compartir una serie de películas, programadas con criterios sistemáticos, con lecturas que acompañaban las exhibiciones, y además también en algún momento con la asistencia a películas que miembros del Cine Club estaban comenzando a hacer en ese momento, le dio una importancia que avanzó más allá de las fronteras de Cali. En ese momento teníamos visitas de gente que después se volvió tan importante en la crítica cinematográfica en Colombia como Juan Diego Caicedo, como Diego Rojas (que luego fue crítico de cine, ahora es actor o casi toda su carrera fue actor). Y el Cine Club nuestro les sirvió de referencia para montar cine clubes en Bogotá como el de la Universidad Tadeo Lozano, en donde el cine había adquirido mucha importancia, así como los estudios de comunicación. Hay que recordar que allí trabajó Jesús Martín Barbero. Jesús había llegado a comienzos de los setenta y había influenciado a muchos jóvenes, incluso en territorios como el goce del cine, la recepción cinematográfica. En Medellín también teníamos vínculos con cine clubes (como el Cine Club Mundo Universitario, el Cine Club de Aguirre) con los que manteníamos un cierto diálogo, así fuera interrumpido. Eso prueba que la referencia del Cine Club nuestro se extendía fuera de los límites de Cali.

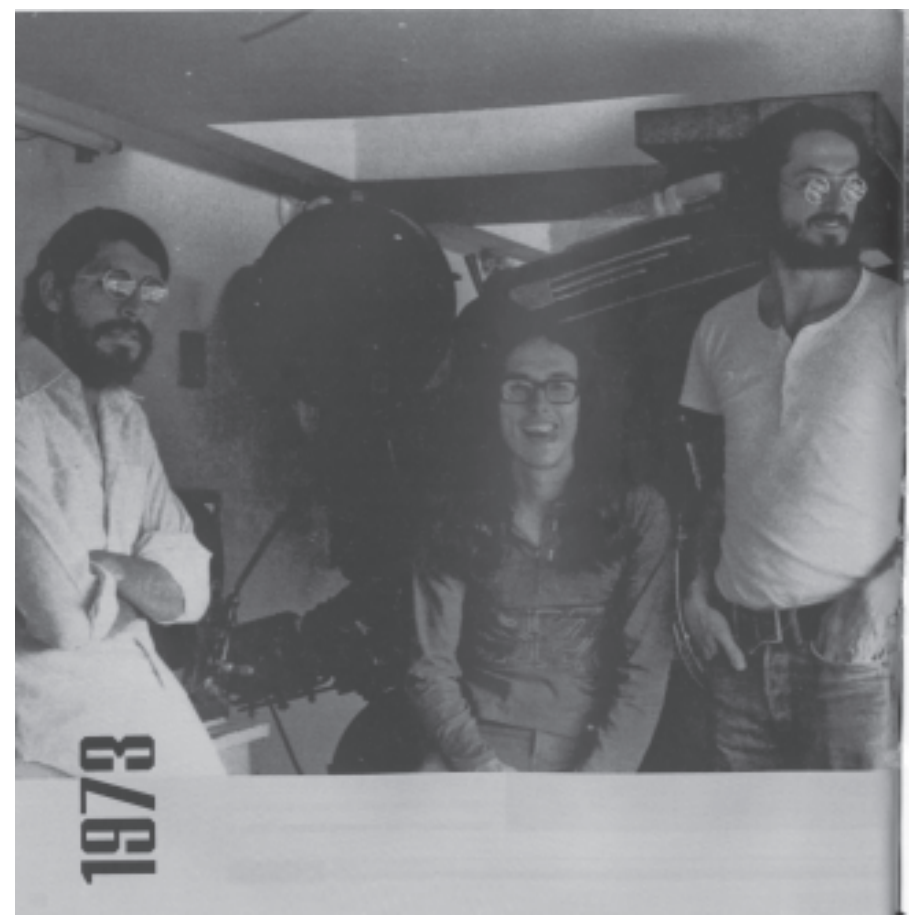

H.T.: ¿Estarías de acuerdo en que el Cine Club recogió la marginalidad artística de Cali?

R.A.: Es posible que sí, pero no en términos absolutos. No era lo único que había en ese momento para gozar o como punto de encuentro. Yo creo que muchos artistas de la época, gente que hacía teatro, gente que hacía música, gente que estaba vinculada al rock inclusive, así como personas pertenecientes a otros ámbitos, hasta deportistas incluso, eran asistentes asiduos. Personas que sin estar vinculadas directamente al cine, consideraban sin embargo que la cultura son muchas cosas, no solamente la rama en donde trabajaban. En ese sentido, sí fue un lugar que recogió o canalizó la necesidad de ver cosas nuevas y organizadas. Lo único que se hacía en el Cine Club era ofrecer textos de interpretación cinematográfica y una programación sistemática de unas películas que difícilmente se programaban o que eran programadas en el caos y en el desorden de la cartelera comercial. 
H.T.: ¿También mencionabas en tu respuesta, no en esta última sino en la anterior, la relación del Cine Club con otros cine clubes de Colombia. ¿Qué relación había con otros cine clubes de Cali?

R.A.: En Cali había una relación de oposición, había una relación de diferencia. El Cine Club de Cali comenzó en abril de 1971, a pocos meses del 26 de febrero, del histórico 26 de febrero de 1971 y a pocas cuadras donde se dio la batalla por la defensa de la Universidad pública (y en la que murió Edgar Mejía, a quien todos conocíamos como Jalisco, a quien todos queríamos). Esto lo digo porque uno de los públicos más numerosos y más asiduos era el de estudiantes de la Universidad del Valle. Y el Cine Club Nueva Generación, que funcionaba en el Teatro Calima, empezó en 1972, un año después, y había una rivalidad que podía entenderse como rivalidad de gente que vendía el mismo producto: cine a la misma hora, en la misma ciudad, pero en diferentes sectores, diferentes barrios. Había también ahí una connotación simbólica en el tipo de gente que iba al norte, a este Cine Club Nueva Generación al Teatro Calima y en la gente que iba al sur, al Cine Club nuestro: estudiantes de la Universidad del Valle, muchos de ellos con ideas de izquierda, incluso gente que venía del hippismo, que en ese momento estaba fresco, gente que en ese momento tenía otro tipo de visión de vida, muy diferente de las que tenía el público, creo, que iba al Cine Club de Calima. Ahora bien, la diferencia no se expresaba sólo en el tipo de público o en la situación geográfica de los cine clubes sino también porque la programación del Cine Club Nueva Generación era completamente distinta a la programación del Cine Club nuestro. La idea que ellos tenían del cine, en ese momento, estaba muy ligada a la literatura. Las programaciones de ellos se basaban generalmente en hitos importantes en la historia de la literatura; y lo que no era así podría entrar en la denominación de lo que Truffaut llamó, en su momento, el «cine de calidad», precisamente en un manifiesto en donde él se oponía a ese cine, un cine tradicional, un cine conservador. Por ejemplo, Claude Lelouch era muy importante, para el Cine Club de Cali no. Aparentemente habría una contradicción en ser un cine club que quería ser de vanguardia. Pero nosotros programamos mucho cine americano. Éramos, sin habérnoslo propuesto con ese epíteto, cahieristas, porque seguíamos los dictámenes, quizás filtrados o mediados por otro tipo de publicaciones, de la revista parisina Cahiers du Cinéma. Esta revista fue la que primero descubrió a los directores americanos y les dio la connotación de autores. Los primeros que hicieron esa sistematización fueron los franceses, ni siquiera fueron los mismos gringos. Yo creo que por medio de la revista peruana Hablemos de cine y de otras revistas que eventualmente nos llegaban, latinoamericanas, nosotros resultamos siendo cahieristas, resultamos dándole mucha importancia a directores como Alfred Hitchcock, como Ingmar Bergman, como John Ford, como Fellini, como Buñuel. Una de las perspectivas o criterios más constantes en nuestra programación era el criterio de autor. Entonces, las programaciones estaban conformadas por tres o cuatro películas de un autor. En ese sentido, nosotros teníamos una visión, quisiera decir, más moderna del cine y no esa visión tan apegada a lo literario como tenía el otro cine club.

H.T.: Me gustaría volver sobre un punto. Vos mencionabas a deportistas que encontraban en el Cine Club una respuesta a sus necesidades. ¿Vos cómo caracterizarías esas necesidades? ¿Y en qué se diferenciaban éstas de las del cine club del teatro Calima? ¿Por qué los unos iban al otro y otro tipo de público venía acá?

R.A.: Bueno, lo dije pensando en que yo recuerdo que muchos (bueno, no muchos, pero digamos diez, que para mí eran muchos), eran gente que acababa de hacer deporte en el Centro Deportivo Universitario, el llamado CDU de la Universidad del Valle, y uno los veía llegar en pantaloneta, sudados, inclusive mujeres que llegaban de hacer deporte en la misma universidad. Necesidades deportivas no les suplía el Cine Club: yo creo que la necesidad que les suplía era de tipo social cultural. Les brindaba un escenario, primero de encuentro y segundo de alimentación cultural por medio de las películas que veían, por medio de los textos que recogían para leer después. A ese tipo de necesidades me refiero, no a las necesidades deportivas.

H.T.: Claro, claro, de acuerdo.

R.A.: Aunque es posible que en algún momento haya respondido a eso como, por ejemplo, la película Ciudad Dorada de John Huston, que era sobre un boxeador. Pero específicamente me refería a que eran públicos diversos que encontraban allí un canal que les permitía gozar una parte de cultura que ellos valoraban, que les parecía importante, pero también con la que se entretenían y gozaban. También 
estaba, por supuesto, el hecho social de encontrarse ahí con sus pares. Porque lo importante también del Cine Club era que el encuentro del sábado a medio día te permitía casi programar el fin de semana; allí la gente se encontraba para ver qué hacían, si iban para una finca, si se dedicaban a estudiar, si se iban de rumba. Allí había gente que estudiaba el fin de semana y empezaba en el Cine Club o gente que iba simplemente a almorzar y luego terminaban en otra cosa. Pero era un punto de encuentro: por lo tanto, yo valoro el aspecto social que brindaba el Cine Club.

H.T.: Sí, de acuerdo. Fíjate en esto, es curioso, yo era uno de los asistentes a este Cine Club y nunca lo hice con conciencia de nada, simplemente me gustaba ir porque ponían música de Richie Ray a todo volumen y porque repartían unos papelitos con la historia del autor y una reseña de la película y una cierta orientación. Te lo estoy planteando a propósito de lo de las necesidades: me parece que si uno trata de encontrarle un mínimo común denominador a todo esto que pasaba allí era, finalmente, una sensibilidad de la época que le permitía estar a uno en una misma actividad con gente que hacía deporte, con pintores, con fotógrafos, con gente que metía marihuana, con gente que le encantaba la música...

\section{R.A.: Con pandillas. La Barra del Triángulo iba.}

H.T.: Sí, La Barra del Triángulo. Entonces lo que había allí era una identificación en la sensibilidad de la época, eso que la gente más o menos llama el espíritu de los años sesenta. Había una cierta complicidad casi que corporal, física y unos supuestos ideológicos compartidos.

R.A.: No solamente era ideológica, era una sensibilidad de emociones compartidas.

H.T: Claro, exactamente. Entonces tal vez era eso lo que no encontraban en el otro Cine Club. $Y$ quizás sea ese también el rasgo diferencial que finalmente separaba las dos actividades, la del Cine Club del Teatro Calima y la de este Cine Club. ¿Siempre funcionó en el Teatro San Fernando?

R.A.: Bueno, la historia del Cine Club de Cali con ese nombre sí está asociada mucho al Teatro San Fernando. Cuando nos vamos de ahí, después de la muerte de Andrés Caicedo, no nos vamos por eso, porque se haya muerto Andrés y por lo tanto el Cine Club va a entrar en decadencia. Nos vamos porque coincidió con la remodelación del Teatro. Entonces, unos meses después de que se muere Andrés coincidió con que el Teatro San Fernando se cerró para remodelarlo, cosa que duró varios meses..., entonces nosotros los que quedábamos...

H.T.: ¿No será que lo remodelaron para liberarlo del espíritu de Andrés (risas) que quedaba flotando, el fantasma de Andrés? (Risas).

R.A.: Ah, pues sí (risas). Sin embargo no pudieron exorcizarlo porque luego hubo allí un Cine Club que se llamaba Andrés Caicedo y hubo varios intentos de montar una cosa parecida a la que hizo Andrés. Pero nos pasamos a la sala de la Cinemateca La Tertulia. Lo que pasa es que el sitio geográfico del Teatro San Fernando era una de las cosas importantes de ese Cine Club. Al pasarlo a La Tertulia, que era demasiado lejos de la quinta, que tenía pocos servicios de rutas de buses, que además hacía que tuvieras que caminar a medio día, con ese sol, antes de las doce y media que comenzaba y luego salir a las dos de la tarde, con ese otro sol a coger bus en la calle quinta, yo creo que eso influyó mucho en varios de los asistentes más fieles de nuestro Cine Club, y poco a poco, por inanición, porque no pagaba lo que costaba, el Cine Club fue muriendo a pesar de que tratamos de estirarlo lo que más pudimos, con material y películas que conseguíamos prácticamente gratis. La sala no nos cobraba, o en ese momento sí nos cobraba pero era una deuda, que llegó a varios miles de pesos del momento, finalmente condonada por la dirección de La Tertulia. Nunca la pagamos. Eso para decirte que el Cine Club muere por inanición y por haber perdido sobre todo el lugar del teatro San Fernando.

H.T.: Sí, justamente sobre esto. El hecho de cambiar el Teatro San Fernando, que queda en un lugar estratégico, porque la Universidad del Valle está allí, al pie, porque está la quinta, porque están las rutas de buses, es decir, es un lugar muy importante, paro pasarlo a La Tertulia...

\section{R.A.: El Parque Panamericano...}

H.T.: El Estadio Olímpico, el Hospital, es decir, es un centro neurálgico de la vida de la ciudad. El hecho de cambiarlo a La Tertulia implicaba todas estas dificultades que has señalado. ¿Pero no creés que también implicaba una cierta exclusión del tipo simbólico? Ir sudando al Teatro San Fernando está bien, pero ir sudando a La Tertulia... y los marginales que iban al 
Teatro...porque también funciona la idea del lugar sacralizado, como ocurre con las librerías, a las que hay gente que no entra porque no se considera digna. Ir a La Tertulia era entrar a un lugar con una simbología que no es exactamente la del Teatro San Fernando.

R.A.: Claro, claro, es decir, es posible que hayamos perdido, precisamente, a ese tipo de marginalidad que en el Teatro San Fernando se sentía a sus anchas, inclusive a sus anchas para consumir marihuana, por ejemplo. Yo recuerdo que los más fieles seguidores eran muy amigos nuestros y los que iban a La Tertulia terminaron siendo nuestros amigos más cercanos y uno no sabía si lo hacían por solidaridad o porque les gustaba ver las películas en las condiciones nuevas de la Cinemateca de La Tertulia. Pero para referirme a la pregunta anterior hay que recordar que el Cine Club de Cali es un cine club que empieza Andrés Caicedo pero que tiene un antecedente en el Cine Club del TEC (Teatro Escuela de Cali). Él le propone a los del TEC, a Enrique Buenaventura, hacer un cine club en 16 y en 35.En 16 se hace en la sala del TEC, pero en 35 se hace en el Teatro Alameda. Él abre el Cine Club en 1970 con el nombre de Cine Club del TEC y ese esquema que él usa de programación, una programación sistemática, una programación por géneros, por autores, es el mismo que él lleva al Cine Club de Cali. Lo cierra a finales de 1970, también por inanición, porque se le fue la mano (estaba aprendiendo cómo se programaba un cine club) en el número de películas del Oeste que programó. Él era un apasionado de ese género, pero el público se terminó saturando. Nosotros llegamos a establecer que si uno programaba más de cuatro películas de un sólo tópico, empezaba una reducción drástica de público. Entonces tratábamos siempre de escoger cuatro películas significativas de cada tema, sea género, sea autor, sea un tema o un país y no pasarnos de cuatro porque cuatro es un mes. Hay que recordar que el Cine Club tenía una programación semanal y eso extendía el tema o el género por un mes y al mes la gente empezaba a cansarse. Hago referencia a eso porque el Cine Club, igualito, en términos de criterio y en términos de cómo se programaba empezó, realmente, en el Teatro Alameda con el Cine Club del TEC.

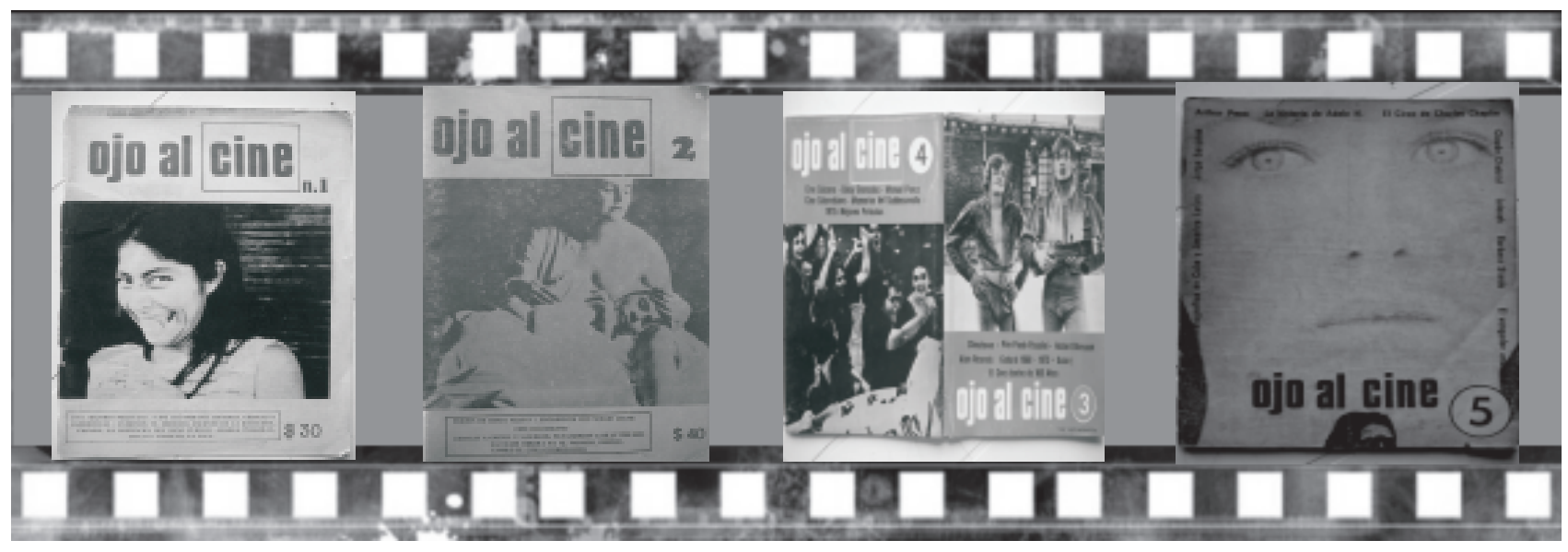

H.T.: Vos has mencionado que los criterios de selección se daban por género, por autor, por país, por temática. ¿Se respetó de manera rigurosa eso? ¿No había también una cierta anarquía programática?

R.A.: No, no. Lo que pasa es que programar cine clubes en Colombia siempre fue muy difícil porque aquí prima el criterio comercial. Bueno, la ventaja para nosotros, los cineclubistas, era que programábamos muchas películas que no eran tan demandadas en el momento, es decir, no eran películas de estreno, de alguna manera eran reprises. Programar en ese momento era fácil porque nosotros no dependíamos mucho de los estrenos. Las películas que nos daban para estreno eran las que los distribuidores o los exhibidores habían pensado que no iban a «pegar» en Cali, que no iban a tener ninguna demanda.

Entonces nos las daban, pero la mayoría de películas que nosotros traíamos eran películas que ya habían pasado por el circuito comercial. Realmente nosotros, y sobre todo Andrés, era un ratón de distribuidoras; él descubrió muchas películas, de las que tenía referencia por críticas que él había leído, pero cuyo título no coincidía con el título en inglés o con el título con el que se había dado en México o en España o en ciertos países de latinoamérica, donde les cambian el nombre. Una película de la que uno tenía una buena referencia la conocía con otro título, pero Andrés era un especialista en descubrir las películas importantes que de otra manera nadie hubiera descubierto. Cuando ocurría eso, descubrimientos o hallazgos sorpresivos, la programación variaba, y se hacía como una especie de pot- 
pourri: cuatro películas, cualesquiera, aparentemente sin relación, pero que era importante darlas en ese momento porque se habían acabado de descubrir, porque además queríamos ver, puede haber sido una película muy famosa que no habíamos visto y entonces, como no podíamos verla en exhibición privada, porque rara vez pudimos hacerlo, entonces la teníamos que ver con el público. Era como un albur. Que la película gustara o no era secundario pues lo importante era que la veíamos. La veíamos con el público.

\section{H.T.: La descubrían con el público.}

R.A.: Sí, la descubríamos, pero la mayoría de las veces, yo creo que en un $80 \%$, se respetó la programación por un tema, por un tópico, por un género, por autor, por actor también, por país, dimos cine mexicano, dimos cine ruso, al que le llamamos «cine rojo». Bueno, ya no recuerdo qué otro criterio, pero la mayoría de las veces era autor o a veces combinábamos porque el Cine Club llegó a funcionar a toda máquina. Cómo sería el auge y la respuesta del público tan positiva, que nosotros llegamos a tener sábados con tres exhibiciones, una a las diez, una a las doce y otra a media noche.

\section{H.T.: Cine de terror a medianoche, algo así, recuerdo.}

R.A.: Sí, entonces eran diferentes tipos de género, cine de terror a las doce de la noche y por la mañana la combinación no era pasar dos películas de Bergman ni dos películas de Buñuel, pues creíamos que la gente a lo mejor no resistía. Pero si tratábamos de hacer combinaciones probando parejas, algún tipo de relación había entre la que se programaba a las diez y la de las doce. Hubo momentos en que fue una programación abundante.

\section{H.T.: ¿Cómo operaban ustedes, tenían reuniones?}

R.A.: Sí, claro. Lo que pasa es que el Cine Club empezó en 1971 y cuando Andrés se fue a Estados Unidos en 1973, a los dos años y pico, en ese momento había llegado ya Luis Ospina a Cali. Andrés nos había llamado a Luis y a mí a ser parte del Cine Club. Yo no era parte del Cine Club a nivel directivo, yo iba al Cine Club inicialmente porque yo hacía teatro con Andrés. Nosotros hicimos teatro hasta el setenta y dos, o sea que casi siempre yo acompañaba a Andrés a diligencias del Cine Club, no solamente de Teatro sino a diligencias del Cine Club, porque como estábamos montando obras de teatro yo todo el tiempo estaba con él o estábamos con él Jaime Acosta y yo, para hablar de personas concretas. Entonces, hasta 1973 la programaba sólo Andrés; es posible que consultara, de pronto, con Hernando Guerrero, quien le ayudaba en la parte logística. Hernando regentaba Ciudad Solar y a Andrés le fue muy útil esta Institución porque le ayudó al arranque del Cine Club administrativamente. Pero después, cuando Luis Ospina y yo llegamos, que Andrés se fue, ya nos tocó a Luis Ospina y a mí programar el Cine Club. Ahora, los criterios eran iguales; lo que pasa es que el conocimiento que Luis tenía en ese momento del cine era mucho más amplio que el que yo tenía, no solamente porque me llevaba varios años viendo cine sino porque había vivido mucha parte de su vida en Estados Unidos. Pero él conocía el título en inglés y yo lo conocía en español, entonces hacíamos una buena dupla en esa programación. Luego, cuando Andrés vino, que llegó con la pasión o con la emoción de montar la revista, digamos que el Cine Club se volvió más democrático, en el sentido en el que nos reuníamos para dos cosas: para hablar de la revista y para programar el Cine Club. Entonces las programaciones eran consultadas, generalmente había una idea de alguno de nosotros, de un autor concreto porque teníamos conocimiento de que en Cali estaban determinadas copias que estaban siendo llevadas para determinados pueblos cercanos y que era posible programarlas ya. También el criterio era de oportunidad, no había ninguna jerarquía en el orden de los ciclos, sino de oportunidad, disponibilidad. Tratábamos de que no se nos fuera la mano pues teníamos la tendencia a ser programadores de cinemateca. El criterio de programar una cinemateca en otra parte del mundo, no aquí, es que vamos a dar un ciclo de John Ford y lo damos completo, a las 3 una, a las 5 otra, a las 7, a las 9 y nos vamos 3 semanas con John Ford. Pero acá es imposible, nosotros teníamos una exhibición cada semana o cada sábado y no podíamos hacer eso. Si lo hacíamos podíamos llenar un año con el mismo autor. Más o menos funcionaba así.

H.T.: ¿Qué relación había entre la revista y el Cine Club?

R.A.: La revista fue un hijo del Cine Club. Cuando el Cine Club comenzó Andrés publicaba un folletito. 
Los primeros números no fueron un folleto de páginas que se pasan, sino que era una especie de plegable inmenso, yo creo que con más de 16 páginas, que fue un número de Godard. El primer ciclo que dio el Cine Club de Cali, en Abril del 71, fue un ciclo de Godard. Entonces tú podías desplegar un material que él tituló Ojo al Cine; esa fue una edición que ni siquiera fue numerada. Cuando a él ya le dio la idea de sacar una cosa más sistemática, con cara de revista, fue un folleto que se llamaba Ojo al Cine, que recibió el número 1 , el que tiene en la carátula a Drácula, la película Drácula. Ese número se llamó Ojo al Cine Folleto y posteriormente hubo unas cuatro publicaciones más en donde participamos un grupo de estudio que se había armado con unas 8 ó 10 personas. ¿Qué hacíamos allí? Discutir sobre la película más importante de la semana, hablar sobre ella y finalmente Andrés redactaba el resultado de la discusión. Era una hoja que podía haber sido no solamente de cuatro páginas, a veces fue de ocho o de doce, en donde se hablaba de la película o del autor escogido de la cartelera comercial, no del Cine Club, y tenía una tabla que supuestamente era orientadora para lo que se estaba exhibiendo en Cali. Salieron por lo menos cuatro folletitos de esos entre el 71 y 73 , y en el 74 sale la primera revista Ojo al Cine que está dedicada, sobre todo, al cine colombiano. Ocurrió que un poco antes de que saliera esa revista, la Cinemateca Distrital, comandada en ese momento por Isadora de Norden, había programado una antología o una retrospectiva del cine colombiano muy bien organizada; nosotros habíamos ido en varias ocasiones a verla a Bogotá por el entusiasmo que teníamos por ese descubrimiento, pues para mí era descubrimiento, yo creo que para Andrés también, para Mayolo no tanto porque él había estado mucho más pendiente de lo que se había hecho en Colombia. Con ese entusiasmo que nos daba el cine colombiano en ese momento, decidimos dedicarle el primer número. Allí es donde aparece un artículo que pretendía ser histórico, escrito con Mayolo a dos manos, que se llamó Secuencia Crítica del Cine Colombiano. Obviamente, él había tenido, en ese momento que escribimos el artículo, mucha más oportunidad de ver todas las películas de las que hablamos. Yo actué más como redactor y como una especie de interlocutor para concretar ideas - para pulirlas mejor. La sustancia de ese artículo es un $70 \%$ de Mayolo y un 30\% mío. Ahí se publicaron entrevistas, análisis a películas concretas. Ese número 1 es de los que más se recuerda de los pocos números de la revista.
H.T.: ¿Cuántos números salieron en este formato último?

R.A.: Ese formato ya tenía casi cien páginas. Incluso el número 3 y 4 fue doble y tuvo, creo, más de 130 páginas. En números fueron 5 , pero en ediciones fueron 4 porque una fue doble. La última fue incluso premonitoria porque ya el grupo estaba muy resquebrajado, nos habíamos separado. El último número aparece firmado sólo por Andrés Caicedo y Patricia Restrepo, que se había vinculado desde el 3 y 4 . Es muy significativo que aparezca con un índice. El número 5 aparece con un índice de todo lo publicado en los cuatro números anteriores.

H.T.: Una clausura, un balance.

R.A.: Una especie de clausura, sí. Y justo en ese mismo año en el que aparece se mata Andrés.

\section{H.T.: ¿Cuánto tiempo dura el Cine Club?}

R.A.: El Cine Club dura de Abril del 71 a finales del 77. La fecha exacta no la recuerdo, pero debe ser finales de noviembre del 77.

H.T.: ¿Tenés el sentimiento de que fue una buena experiencia?

R.A.: Sí, sí.

H.T.: Sin duda.

R.A.: No sólo lo tuve siempre sino que lo he tenido con el paso de los años. Yo considero que se ha vuelto más importante y el hecho de que a uno lo busquen para preguntarle sobre esa época, que sea una referencia entre la gente que empieza a programar cine clubes, entre la gente que quiere estudiar cine, etc. a uno le demuestra que fue importante lo que hizo. Incluso en las conversaciones y en las referencias, en los artículos que escriben sobre esa época, es claro que el Cine Club de Cali fue una experiencia que marcó un hito, que fue importante incluso para la vida de muchas personas, para caleños que iban no porque tuvieran una pasión o una disciplina por el cine sino porque les gustaba ir al cine. Muchos de esos amigos o gente que apenas conocí hablan muy bien de esa época, forma parte importante de sus vidas.

H.T.: Ramiro, gracias.

R.A.: (Risas) ¿Eso era todo? 